\title{
El Formalismo Kantiano como solución al Problema de la Información Secuestrada
}

\author{
Alejandro Pérez y Soto Domínguez \\ Economista. Máster en Economía de la Escuela Austriaca. Universidad Rey Juan Carlos, Madrid. Doctor en Economía \\ Universidad Rey Juan Carlos, Madrid. Doctorado en curso en Derecho Universidad de Zaragoza. Docente investigador \\ del Grupo Derecho y Economía de la Universidad Externado de Colombia (Colombia) \\ E-mail: alejandro.perez@uexternado.edu.co
}

Katherine Flórez Pinilla

Economista. Máster en Derecho con énfasis en Derecho Económico, Universidad Externado de Colombia. Docente Investigadora del Grupo economía, gestión, territorio y desarrollo sostenible -GEOS de la Universidad San Buenaventura Cali, (Colombia).E-mail:kflorez1@usbcali.edu.co

\begin{abstract}
Resumen
Este artículo es un producto de investigación que pretende explorar el formalismo Kantiano, acercarse a sus bases epistemológicas, su formulación antropológica y la propuesta institucional que resulta de aquel, para dar solución al problema de información secuestrada en relación con el Derecho y la Ley, planteado en un trabajo anterior. La mirada Kantiana ofrece una plataforma teórica desde la cual es posible establecer las bases de un orden social liberal que permita la convivencia de intereses y la articulación de los mismos desde la noción del Reino de los Fines. La formulación del imperativo categórico como guía de la acción humana y como sustento en la formulación de la ley da bases racionales a una visión moderna del derecho natural y permiten la formulación del mercado como modo de integración y coordinación social espontánea.
\end{abstract}

Palabras Clave: Información Secuestrada, Formalismo Kantiano, Derecho Natural, Reino de los Fines.

\begin{abstract}
This article explores the Kantian formalism, approaching its epistemological, anthropological and its formulation institutional proposal to solve the problem of information kidnapped, raised in a previous work. The look provides a platform Kantian theoretical basis of a liberal social order. This allows the coexistence of joint interests and the same from the notion of the Kingdom of Ends. The formulation of the categorical imperative as a guide to action, and as a basis in formulating rational law supports a modern vision of natural law and allows the formulation of the market as a means of social integration and coordination spontaneous.
\end{abstract}

Keywords: Kidnapped Information, Kantian Formalism, Natural Law, Kingdom of Ends.

\section{Résumé}

Ce produit expérimental de l'article est destiné à explorer le formalisme kantien, approcher leurs fondements épistémologiques, formulation anthropologique et proposition institutionnelle qui résulte de ce que, pour résoudre le problème de l'information saisie dans le cadre de la loi et du droit, soulevée dans travaux antérieurs. Le point de vue kantien fournit une plate-forme théorique à partir de laquelle il est possible de jeter les bases d'un ordre social libéral permettant la coexistence d'intérêts et les articuler à partir de la notion de règne des fins. La formulation de l'impératif catégorique pour guider l'action humaine et que le soutien à l'élaboration de la loi de base rationnelle donne une vision moderne du droit naturel et de permettre la formulation de mode de l'intégration des marchés et de la coordination sociale spontanée.

Mots-clés: Informations Kidnapped, Kantienneformalisme, Droit naturel, Règne des fins. 



\title{
El Formalismo Kantiano como solución al Problema de la Información Secuestrada*
}

Alejandro Pérez y Soto Domínguez Katherine Flórez Pinilla

\section{INTRODUCCIÓN}

\begin{abstract}
"En todas las épocas, el desarrollo de la libertad ha sido obstaculizado por sus enemigos naturales, el deseo de conquista y el amor al lujo, por el afán de poder de los ricos y la desespera da necesidad de comida de los pobres"
\end{abstract}

Lord Acton (1999, p. 57)

En la tesis doctoral La información secuestrada (Pérez y Soto, 2013), se presentaba el problema de la captura y de secuestro de información por parte del Estado, cuando en su ejercicio se establecían barreras a la creación y a la producción de información de los individuos, quienes en su búsqueda de mejora constante se encuentran en una exploración infinita por refinar sus modos de acción para unir de manera más eficiente medios y fines. Esta tesis identificaba esta propuesta institucional en el denominado falso individualismo, mediante el cual se concibe al hombre como anterior a las relaciones sociales, y en virtud de estos se le cercena desde el método su condición social y natural, proponiéndolo como un lienzo en blanco que no tiene modos de regulación autónomos, sino que en razón de su natural torpeza o rapacidad, debía ser llenado con las características que le eran legadas desde la voluntad del soberano. El secuestro de la información se lleva a cabo por medio del ejercicio del sabio legislador que busca determinar coactivamente todas las dimensiones sociales del ser humano al suprimir la moral como mecanismo de regulación, lo

El artículo es producto de los proyectos: La información secuestrada, Universidad Externado de Colombia; y El orden mercantil sus fundamentos metodológicos e institucionales, Universidad de San Buenaventura, Cali (Col). 
que en términos económicos es cumplido por el planificador centralizado en lo que conocemos como socialismo'.

Para estructurar el secuestro de la información se debía entender la sustitución de la noción de ley natural, por ley positiva. Se mostraba cómo el trabajo de Thomas Hobbes (1997) era la base del proyecto cartesiano que asumía el Derecho como un modo de ingeniería social ${ }^{2}$ en el cual se buscaba establecer un proyecto de sociedad idílica, sin conflictos, basados en el mutuo temor de todos hacia el soberano. Sin embargo, retomando el concepto de Mises sobre la imposibilidad del socialismo y aportando un nuevo concepto adicional sobre información secuestrada, se propuso que el sabio legislador, al igual que el planificador, no logra hacerse con toda la información necesaria para guiar el mundo social y el mundo económico por medio de la regulación. Mas con su acción planificadora de los fines del individuo, logra en numerosas oportunidades impedir la creación de información, alterando la coordinación de la acción humana a escala social, condenándolo a la involución y comprometiendo la sostenibilidad de los seres humanos y posiblemente condenándolos a la extinción o a una vida, pobre, miserable, brutal y corta. Si se asume enserio la analogía de la formación social como un organismo, este es susceptible de nacer, crecer y reproducirse. Justamente, el modo que tiene para poder crecer, casi de modo indefinido es la creación de información, y el refinamiento de la coordinación espontánea de la acción humana a escala global. No obstante, así como puede crecer y reproducirse, también es susceptible de sufrir patologías que le perjudiquen y puedan conducirle a la muerte. Del mismo modo como la creación y difusión de información es la clave para la creación y reproducción de la sociedad, igualmente, su secuestro puede ser la clave para su disolución y su muerte.

En este artículo se presentará un esbozo de solución al problema planteado en la tesis doctoral. En esta oportunidad nos serviremos del trabajo de Immanuel Kant (2006) para mostrar cómo desde un esfuerzo eminentemente filosófico, el pensadoralemán logra darle solución a la problemática ilustrada. Veremos

1 Para la definición de socialismo nos serviremos del concepto que construye desde la Escuela Austriaca de Economía, el profesor español Jesús Huerta de Soto. Veamos: "Definiremos el socialismo como todo sistema de agresión institucional al libre ejercicio de la función empresarial. Por agresión o coacción hemos de entender toda violencia física o amenaza de violencia física que se inicia y ejerce sobre el actor por otro ser humano o grupo de seres humanos. Como consecuencia de esta coacción, la persona, que de otra forma habría ejercido libremente su función empresarial, en evitación de mayores males, se ve forzada a actuar de una manera distinta a como habría actuado en otras circunstancias, modificando, por tanto, su comportamiento y adecuándolo a los fines de aquel o aquellos que le coaccionan" (Huerta de Soto 1992, p. 87).

2 "Una acción plenamente racional en el sentido cartesiano del término exige el exhaustivo conocimiento de todos los hechos relevantes. Un proyectista o ingeniero, para poder organizar los objetos materiales y conseguir el resultado que pretende, necesita conocer todos los datos di disponer de todos el poder necesario para controlarlos o manipularlos. Pero el éxito de la acción en sociedad depende de un cúmulo de hechos particulares muy superior a los que cualquiera puede conocer. En consecuencia, toda nuestra civilización se basa, y debe basarse, en nuestra creencia mucho más que en lo que podemos conocer como verdadero en sentido cartesiano" (Hayek 2006, p. 30). 
quebasándose en la obra de Kant (2006) es posible corregir el falso individualismo en su mirada epistemológica. Esto toda vez que se retomar al individuo al interior de las relaciones sociales, y como consecuencia de esto, se logra restaurarle su condición natural y social. Al mismo tiempo, se podrá apreciar que en virtud de esta apuesta epistemológica es posible establecer un orden social armónico partiendo del individuo y su capacidad de autocontención de la conducta; además, se propondrá que la institución del derecho y la ley como no orientada hacia la consecución del fines específicos totalizantes, como la maximización de la riqueza, la magnificación del poder del estado, la eliminación de clases, u otros; sino que por el contrario, dirigida a servir de un garante, el cual brinde un margen de acción bajo el que cada individuo puede decidir espontáneamente cómo coordinar medios y fines de modo autónomo .

En la estructura Kantiana, podrá verse un sustento de corte racional al derecho natural, el cual pretende establecer una conexión con la estructura moral del individuo y ser expresión de esta. Como resultado, el individuo se ve libre para emprender sus empresas y propósitos, y al margen de estos se va generando información de modo libre y espontáneo, de modo que el organismo social logra refinarse, toda vez que se van generando nuevos modos de hacer que se cristalizan en una coordinación de la acción humana más elaborada, y como consecuencia de esto, se generará un crecimiento tecnológico que permitirá una vida más cómoda y posiblemente más larga para los seres humanos.

La obra del filósofo alemán, desde esta perspectiva, puede interpretarse como un insumo fundamental para comprender la propuesta institucional que permea los campos de la ética, la filosofía y el derecho, mostrando nuevamente sus vasos comunicantes, tal como se hacía en la antigüedad con los estoicos o en la edad media con la Escuela de Salamanca y en la modernidad con la Ilustración Escocesa. El abordaje apunta sin lugar a dudas desde una visión liberal a lo que se denominase como gran sociedad (Adam Smith,) una sociedad abierta (Karl Popper, o simplemente una sociedad libre (F.A.Hayek).

\section{EL FORMALISMO KANTIANO COMO LEY MORAL O UNA FUNDAMENTACIÓN DE LA METAFÍSICA DE LAS COSTUMBRES}

"Puedes vivir siempre próspero si eres capaz también de tomar siempre la vía recta, si eres capaz de pensar y actuar con rectitud. Estas dos cosas son comunes al alma de Dios y a la del hombre, así como a la de todo animal racional: el no ser impedido por otro y el tener el bien en una disposición y acción justa, y en que ahí cese el apetito".

Marco Aurelio 
Kant (2006) en su Fundamentación para una metafísica de las costumbres propone una estructura formal-racional en la cual buscaba determinarlos cimientos para el establecimiento de una moralidad con base en elementos que corresponden por entero a la lógica formal y alejada de cualquier pretensión empirista. El propósito de esta obra puede ser establecer unos principios generales que pudieran orientar la conducta humana, pero no desde la subjetividad del individuo, ni desde la intersubjetividad de la cultura, sino que siguiendo los presupuestos cartesianos, fuese posible establecer una moralidad con base enteramente racional, alejada del juicio primario del instituto y la pasión que habitaba en todos los hombres por igual. La literatura sobre Kant (2006) y la aplicación de su formalismo ético, así como sus implicaciones jurídicas han sido objeto de innumerables trabajos, no siempre coincidentes, en los cuales el artilugio lógico que diseña el filósofo alemán ha servido por igual para justificar la fundamentación de Estados totalizantes, tales como las visiones de Hegel y Kelsen; así también como para fundamentar el proyecto de una Sociedad Abierta, tal como Popper la entiende, no fundamentada en el absoluto monolítico, sino, cimentada bajo el arbitrio del individuo como dueño de sí, y en su condición de heredero y constructor del mundo.

La postura aquí expuesta es que la mirada de Kant (2006) puede asimilarse como la permanencia de la tradición Estoica de los Antiguos Latinos Marco Aurelio, Epicuro, Cicerón y sus consecutivos modernos en Adam Smith, Adam Ferguson, David Hume y F.A. Hayek (1997, 2007). En esa medida, su esfuerzo filosófico se dirigirá entonces a establecer una base racional, esto es, una justificación a los mandatos antiguos de contención de las pasiones, la moderación de la conducta y el fortalecimiento del arbitrio interno como programa moral de la humanidad como principio general del individuo, lo cual en términos de lo político se compagina también con el rechazo que se guardaba a la tiranía y la servidumbre como principio elemental de la organización del Estado y la formulación del Derecho Natural ${ }^{3}$. Pero se busca establecer estos principios como una deducción lógica, más que como valores absolutos.

Tal como lo propusiera Garrido (2005) en su Introducción a la Fundamentación, la concepción ética de pretensión objetivista de Kant es ante todo una "ética para la

3 Aunque implícitamente Kant pueda aceptar los principios de los estoicos y proponerlos como parte de su programa moral, al mismo tiempo establece que estos han de requerir de un criterio racional para ser aceptados. Esto en tanto los principios que guían la conducta no deben ser ciertos, ni aceptados por sí mismos, sino por el ordenamiento racional, al cual se pretende acercar. Veamos: "Algunas cualidades incluso resultan favorables a esa buena voluntad y pueden facilitar sobremanera su labor, pero pese a ello carecen / de un valor intrínseco e incondicional, presuponiéndose siempre una buena voluntad que los circunscriba la alta estima profesada - con toda razón por lo demáshacia dichas cualidades y no permita que sean tenidas por buenas en términos absolutos. La moderación en materia de afectos y pasiones, el autocontrol y la reflexión serena no sólo son cosas buenas bajo múltiples aspectos, sino que parecen constituir una parte del valor intrínseco de la persona; sin embargo, falta mucho para que sean calificadas de buenas en términos absolutos (tal como fueron ponderadas por los antiguos)"(Kant,2006, p. 64) 
libertad", quiere decir esto que es un programa para el ejercicio pleno del arbitrio humano en toda su extensión. Se trata de la aplicación del principio de la autonomía como origen del orden social. Los términos griegos nomos y heteros hacían referencia a "ley" y "otro" respectivamente. Esto es, una ley impuesta exógenamente, fuera del arbitrio del hombre, a esto Kant lo llama heteronomía. La mirada kantiana se dirige a entronar al hombre como legislador de sí mismo, ya no motivado por la ley que esta fuera de él, sino desde su autonomía (autos "uno mismo" y nomos "ley"). Tal como lo plantease C.B. Macperson (2005):

El individuo -se pensaba- es libre en la medida en que es propietario de sus propias capacidades. Lo esencial del ser humano es la libertad de dependencia de voluntades ajenas, y la libertad es función de lo que posee. La sociedad se convierte en un hato de individuos libres e iguales relacionados entre sí como propietarios de sus propias capacidades y de lo que ha adquirido mediante su ejercicio. La sociedad está hecha de relaciones de intercambio entre propietarios (p.15).

Lo anterior, no debe confundirse con la concepción Hobbesiana del hombre sin límites, y bajo una concepción positiva de la libertad, en la que él tiene a disposición todos los medios para alzarse con sus deseos, sino que corresponde más bien, a un ejercicio en el que el hombre es capaz de imponerse sobre sí unas limitaciones, a la luz de las cuales su conducta no obstruya la búsqueda de la felicidad por parte de los demás hombres. Tal como lo demuestra Pérez y Soto (2013) en su Tesis Doctoral de Economía "La información secuestrada", el vacío moral como efecto del falso individualismo posibilita a Hobbes (2005) edificar un Estado Absoluto que suprima al individuo como entidad política constructora del orden social moderno.

Entendido de este modo, si bien en Hobbes (2005) la ausencia total de un mecanismo de contención de la conducta, hace imperativo la creación de un Estado Absoluto que someta la condición rapaz de los hombres, del mismo modo en Kant la autocontención del individuo hace que también se suscite la limitación del poder del Estado y su capacidad de intervención sobre el ámbito privado del individuo. Se trata de una propuesta en la que se asume que el hombre ya es mayor de edad, que no requiere un tutor externo, que puede dar cuenta de sí. Llevando con esto a la práctica la frase de Horacio de Sapere Aude, en la que el hombre no da rienda suelta a sus pasiones, sino que se vale de su propio entendimiento para contenerlas y moderar su conducta. El filósofo de Könisberg exhibe así en su obra una especie de Estoicismo con empaque racionalista, pues aunque el método que privilegia es el uso de la razón, el componente sustantivo, el que logra definirlo es un enfoque liberal, basado en la contención de las pasiones.

En Kant se pueden encontrar nuevamente los vasos comunicantes entre moralderecho-ley, bajo los criterios de igualdad ante la ley, universalidad de las normas y libertad negativa. En la medida que se ha comprendido que los individuos son los llamados a construir el orden social y que el ejercicio de su libertad individual es la 
clave para la generación de información, mediante la cual se genera la coordinación de la acción humana a gran escala. Se trata en definitiva de establecer una suerte mirada sobre el derecho natural, del derecho como contención, ya no sobre las bases del derecho de autoridad de la divinidad, sino sobre las bases que provee la economía al explicar cómo los órdenes espontáneos funcionan de la mejor forma posible cuando se les deja en libertad, al permitir a cada individuo la búsqueda de lo que él considere que es la libertad, así como los medios para llegar lo que en esta se representa. La fórmula kantiana puede entenderse como que la regulación para el individuo, se entiende como la limitación de la conducta, allí donde la moral puede ser frágil y donde la conducta puede ser potencialmente dañina para la búsqueda de los fines de sus congéneres.

\subsection{La buena voluntad como arquetipo moral}

Kant (2006) propone en su estudio un fundamento de la moral con bases racionales, para ello propone la edificación de un arquetipo que como filtro de la razón pueda al hombre común establecer un filtro sobre las normas morales que posee y establecer cuáles de ellas pueden ser sujeto de aceptación como principio general de orientación de la conducta. Este arquetipo lo recoge bajo el concepto de "buena voluntad", la cual se levanta por encima de las costumbres, de las pasiones de los hombres y de su subjetividad. Se trata de un instrumento de aplicación universal, de una medida bajo la cual valorar tanto las acciones del hombre, como las "normas" socialmente construidas para ponderar tales acciones. Veamos:

Cada cosa de la naturaleza opera con arreglo a leyes. Sólo un ser racional posee la capacidad de obrar según la representación de las leyes o con arreglo a principios del obrar, esto es, posee una voluntad. Como para derivar las acciones a partir de leyes se requiere de una razón, la voluntad no es otra cosa que razón práctica. Si la razón determina indefectiblemente a la voluntad, entonces las acciones de un ser semejante que sean reconocidas como objetivamente necesarias lo serán también subjetivamente, es decir, es decir, la voluntad es una capacidad de elegir solo aquello que la razón reconoce, independientemente de la inclinación” (Kant, 2006, p. 91).

Ahora frente a esto Kant se preguntará: “¿Cuál puede ser esa ley cuya representación, sin tomar en cuenta el efecto aguardado merced a ella tiene que determinar la voluntad, para que pueda ser calificada de "buena" en términos absolutos y sin paliativos?" (2006, p. 76).

Para responder a esto, Kant (2006) recurre a un principio de aplicación general de máximas, o la moderación de la conducta por medio de la utilización de un espectador imparcial, o de Juez en el pecho, ambas figuras que habían enunciado Adam Smith en su Teoría de los Sentimientos Morales. El mecanismo es sencillo y consiste en probar la admisibilidad o no de la conducta del hombre, sometiéndolo a la prueba de universalidad. Esto es, si la conducta que asume un hombre pudiera convertirse 
en patrón general de conducta, sería admisible por quien ejecuta la acción. Así un hombre sabrá si es moralmente adecuado mentir, si está dispuesto a que todos asuman como norma general de conducta la mentira. Asimismo, será considerado como algo bueno el cumplimiento de una promesa, en la medida en la que el hombre espera siempre que sus congéneres cumplan la palabra empeñada. Esto mismo cabe para el despojo, el respeto a la propiedad, entre otros. En palabras de Kant (2006):

Yo nunca debo proceder de otro modo salvo que pueda querer también ver convertida en ley universal mi máxima. Aquí es la simple legitimidad en general (sin colocar otro fundamento para ciertas acciones una determinada ley) lo que sirve de principio a la voluntad y así tiene que servirle, si el deber no debe ser por doquier una vana ilusión y un concepto quimérico; con esto coincide perfectamente la razón del hombre común en su enjuiciamiento práctico, ya que siempre tiene ante sus ojos el mencionado principio (p. 76).

Bajo este principio, Kant (2006) logra dos objetivos que podrían aparentar no ser convergentes. De una parte, somete la moralidad a un principio de lógica universal, ofreciéndole rigurosidad y coherencia y de otro lado, ofrece al hombre común un criterio sencillo y de fácil comprensión mediante el cual evaluar sus modos de acción, así como establecer una balanza al acervo normativo que su formación cultural le ha legado. Precisamente se ha llamado "una metafísica de las costumbres", entre otras razones, debido a que su propósito incluye el alzarse por encima del edificio cultural y someterlo a la prueba de la lógica racional. Así la prueba de universalidad se encuentra servida en Kant (2006), bajo la mirada vigilante de la lógica, al alcance del hombre común, y tan sencilla como implacable. Como forma de corolario, Kant (2006) expondrá:

Y bien pronto me convenzo de que, si bien puedo querer la mentira, no puedo querer, empero una ley universal de mentir, pues, según esta ley no habría propiamente ninguna promesa, porque sería vano fingir a otros mi voluntad respecto de mis futuras acciones, pues no creerían ese mi fingimiento, o si, por precipitación lo hicieren, pagaríanme con la misma moneda; por tanto mi máxima, tan pronto como se tornase ley universal, destrúyase a sí misma (p.76).

Si bien Kant (2006) establece que sus reflexiones sobre la moral y la "metafísica de las costumbres", se encuentran por completo separadas de cualquier noción antropológica y que se debe únicamente al mundo de la lógica y los juicios a priori, en las citas anteriores, y como parte de la prueba de universalidad que él propone se encuentra implícito un principio fundamental: Todos los hombres son iguales. Así en tanto iguales, sus acciones deben ser juzgadas con la misma medida y sometidas a idéntica lógica. Su conducta podrá ser sujeto de admiración o censura bajo similares ponderaciones y normas de aplicación general. Siendo así, lo que es cierto como modo de orientar el arbitrio interno, contener las pasiones y guiar la autonomía del individuo, se puede aplicar del mismo modo al "Derecho"- entendiendo este como 
legislación externa al hombre-, ya que el respeto a la propiedad, el respeto a la vida e integridad del individuo, entre otras normas de contención de la conducta, pueden ser asimiladas a una extensión de esta norma de la lógica moral, pero no sujeta ya a la compensación interna del hombre, sino propuesta desde la capacidad coactiva del Estado, establecida como garante de una moral falible y de una conducta altamente propensa a separarse de los juicios morales y corromper su conducta. Kant (2006), bajo este examen lógico logra proveer una base por entero racional a uno de los principios del Derecho Natural que conocemos al menos desde la Roma Antigua: La igualdad de las personas ante la ley.

\section{LA ÉTICA COMO PROBLEMA: DEL PROBLEMA SEMÁNTICO, AL PROBLEMA DE LA FELICIDAD}

En la tradición occidental antigua, la ética contenía dos tipos de significaciones: en la primera se tendía a cómo alcanzar la felicidad, tal como puede apreciarse en la noción construida por Aristóteles bajo su concepto, se identificaban una vida moralmente virtuosa, con una vida feliz, así también la podemos encontrar en la obra de Epicuro, que identificaba una vida feliz como una existencia placentera. En la segunda se tenía como meta alcanzar una noción de perfección, tal como la proponían los Estoicos. Entre estas dos definiciones puede apreciarse una suerte de dicotomía entre el "eudonimosmo" y el "perfeccionista". Esta especie de bifurcación persiste hasta nuestros días, ya que puede valorarse la bondad moral de los actos, desde la utilidad que estos proveen o tomando en consideración su calidad intrínseca. Así, los caminos de la ética se dividen entre el utilitarismo consecuencialista o el intuicionista. Juzgando la calidad de las consecuencias, o la aceptación de los métodos. Aunque los teóricos actuales de la ética pueden proponer numerosos matices a esta división, aún es posible establecer ese tipo de agrupaciones entre juzgar las acciones por los resultados o por sus métodos.

Para el caso de Kant (2006), su postura obedece más al juzgamiento de los métodos utilizados por el hombre, que a la efectividad de los mismos. Esto se encuentra vinculado, una vez más con una visión antropológica plenamente establecida, en la que se entiende al hombre como un sujeto que tiene desarrollo propio de sus preferencias y de la escogencia de sus métodos. Es dueño de sí, decide en cada momento qué es lo mejor para él, sin necesidad de un tutor que le imponga un programa de acción exógeno; el hombre es mayor de edad. Al concebirle soberano de sí mismo, no es menester juzgarle por sus deseos, pues estos forman parte de su ámbito íntimo, frente a lo cual solo él responde. La construcción ética, las posibilidades de censura o aplauso van dirigidos hacia los métodos que este pueda emplear en la consecución de sus deseos. Deducido de esto, es posible establecer que la ética, el problema de la libertad y el problema de la búsqueda de la felicidad, se funden en Kant (2006) y se resuelven desde la postura antropológica de la igualdad entre los hombres.

Desembocamos ahora en el concepto de los imperativos, como una derivación 
ética vinculada con el problema de la búsqueda de la felicidad.Por esta vía, Kant (2006) lentamente se acerca, desde la ética a la enunciación del problema material del hombre, no sólo de cómo debe buscar la felicidad, sino acerca de la aceptación o censura de la utilización de los medios para hacerlo; nos conduce, tal vez sin saberlo al problema fundamental de la Economía, a saber: la utilización de medios para acceder a fines; al mismo tiempo que formula el problema elemental del Derecho: la aceptabilidad o restricción en el uso de los medios para acceder a los fines. La estructura que plantea Kant (2006) no es filosófica en términos aislados, sino que compete a la raíz misma del derecho, de la economía y de la combinación de estos. La deducción que podemos extraer de allí es que para que un sistema pueda examinar de manera consistente las normas y leyes que atiende a la Moral, la Ley y el Derecho, estas deben pasar el filtro de la lógica y de atender siempre a un principio elemental de Coherencia, que lleva consigo el concepto de persona de los antiguos romanos y la igualdad ante la ley.

\subsection{Imperativo categórico e hipotético: fines y métodos bajo el filtro de la Ética Pura}

\subsubsection{El concepto de imperativo.}

Kant (2006) al introducir su noción de imperativo, recalca de manera insistente en la naturaleza del problema que lo acompaña como un problema de orden enteramente forma 1, que debe ser decantado por conceptos a priori, separado de cualquier fórmula empírica o concepto antropológico. Curiosamente tras insistir en ello, paso seguido entra a señalar - como axioma antropológico fundamental- que la naturaleza humana no se orienta ciegamente por el instinto o el apetito, que no lo gobierna el reino de los sentidos. Es decir, que el hombre, tal como él lo entiende no es el mismo personaje Selfishness de Hobbes (2006), sino que por el contrario, se parece más al personaje del Selflove de Adam Smith (2004) y su Teoría de los sentimientos morales. Es más, el hombre no sólo no es presa de sus apetitos inmediatos, sino que es capaz de elegir entre lo agradable que le señala el instinto, y lo que él pueda establecer como bueno, más allá del simple fenómeno del deseo fisiológico. La conducta humana se debe, en todo caso, a la acción movilizada por la representación de leyes- morales- que no atienden al aspecto inconsciente, sino que son la manifestación de la capacidad de discernimiento y elección en el hombre. Entendido así la forma o representación de esta ley, es la que él llama Imperativo. Siendo el concepto alrededor del cual construye su reflexión posterior.

\subsubsection{Tipos de Imperativo.}

Los imperativos son en palabras de Kant (2006) fórmulas de determinación de la acción y de acuerdo con el modo en la que la determinan pueden dividirse en dos grupos: En el primero, bajo concepto de Imperativo Categórico, se propone Una 
acción por símisma, sin referencia a ningún otro fin, como objetivamente necesaria. Esto significa que es el detonante de la acción, desde una representación en la que se considera que un fin es bueno en sí mismo, sin que medie más justificación, simplemente es la última representación del deseo. En el segundo, bajo el concepto de Imperativo Hipotético, se entenderá la representación que motiva a una acción, pero en razón de que esta se presenta como buena para alcanzar alguna otra cosa, más no se considera buena en sí misma, sino como un simple medio.

El imperativo dice, pues, qué acción posible por mí es buena, y representa la regla práctica en relación con una voluntad que no hace una acción solamente porque esta sea buena, porque el sujeto no siempre sabe que es buena y también, aun cuando lo supiera, pudieran sus máximas ser contrarias a los principios objetivos de la razón práctica (Kant, 2005, p. 98).

Queda ahora una categoría adicional que se encuentra por completo desprovista de condición moral alguna, en la que únicamente se juzga la calidad de los medios, esto es lo que llama Kant el Imperativo de Habilidad. De acuerdo con este criterio no se trata de si el fin es racional y bueno, sino de lo que hay que hacer para conseguirlo. Aquí el filósofo alemán iguala al médico y al envenenador, pues cada uno persigue un fin y se aplicará a fondo en los medios para conseguirlo, siendo movilizados en ambos casos por imperativos de habilidad. En general, todos los hombres se enfrentan en sus tareas diarias a imperativos de habilidad, puesto que se emprenden a multiplicidad de fines. De hecho, indica Kant, que buena parte de la educación de los padres apunta a brindar a sus hijos numerosas habilidades para poderse revolver con éxito sinnúmero de fines. No obstante, existe un propósito fundamental al que todos los seres humanos se ven enfrentados: la felicidad. En este sentido, el imperativo hipotético es asertótico. Esto en tanto allana el camino para acceder a la felicidad, más depende de la sagacidad del individuo, en tanto pueda elegir los mejores medios para llegar a sus fines. Llegados a este punto y tras la distinción de las categorías de los Imperativos, Categórico, Hipotético y de Sagacidad, Kant enfrenta al hombre con el problema más importante de su existencia, el cual se plantea como naturalmente ininteligible:

Determinar con seguridad y universalidad qué acción fomente la felicidad de un ser racional. Por esto no es posible con respecto a ella un imperativo que mande en sentido estricto realizar lo que nos haga felices; porque la felicidad no es un idea de la razón, sino de la imaginación, que descansa en meros fundamentos empíricos, de los cuales en vano se esperará que hagan de determinar una acción por la cual se alcance la totalidad de una serie en realidad infinita, de consecuencias (Kant, 2005, 102).

El argumento eminentemente apriorístico de Kant, tropieza aquí con el requerimiento del conocimiento de orden práctico -empírico-. Pues se enfrenta a un problema insoluble por medios eminentemente ideales. No existe con certeza ningún medio que pueda asegurar en todo momento y lugar que mediante el uso 
de un método pueda llevar al hombre a la felicidad, ya que el concepto de felicidad es una construcción del pensamiento, de la imaginación nos dirá él en su trabajo. Esta noción aparece en la psiquis humana como la representación de múltiples factores, tales como el desarrollo cultural del colectivo social, en conjunción con las experiencias más íntimas del individuo. Más aún, el problema de los medios se enfrenta naturalmente a una incertidumbre a gran escala, pues el hombre, lejos de ser omnisciente y conocer todos los métodos posibles, dedica buena parte de su vida a refinar los modos de acción para poder tener éxito en sus empresas y propósitos cualquiera que estos sean. También, la definición de la felicidad es un problema de orden eminentemente individual en la que el hombre, desde su capacidad de discernimiento decide qué es lo mejor para él y aunque esté influenciado por el medio social en el que se encuentra inmerso, la definición última de sus fines es un asunto enteramente suyo e inalienable. Kant nos pone aquí frente a un modo de incertidumbre inerradicable en los métodos y los fines. No obstante, esta ignorancia fundamental es que nace justamente la necesidad de una limitación de la moral, ya no sobre los fines, que son competencia de la sabiduría del hombre, sino sobre los medios, el cual vendrá a ser el problema a resolver y donde el imperativo categórico, como idea fundamental que orienta la acción humana asumirá total importancia.

\section{LA NORMA DE LA AUTONOMÍA: DE LA LEY COMO DEBER Y COHERENCIA}

El principio axiomático de Kant sobre la autonomía del individuo, no es una innovación exclusivamente suya, se trata en definitiva de la continuación del espíritu estoico que puede verse a lo largo de todas su obras. El trabajo del filósofo alemán, debe entenderse en muchos sentidos como el eco de conceptos que desde la antigüedad habían sido construidos. Es así como Marco Aurelio (traducido por Daroca) 2010 proponía el ideal romano en términos de aborrecer las dos manifestaciones de la tiranía, tanto ser sirviente, como ser tirano, pues el tirano era esclavo de sí mismo, de sus ambiciones, de su falta de control como ser individual ${ }^{4}$. En Kant se sigue

4 “[...] No ser esclavo ni tirano de ningún hombre (IV 31; cf. Iv 2 y viii 31). En esta declaración se concentra la verdadera dimensión política de la filosofía cultivada por Marco Aurelio; no es un programa político para la reforma del imperio y, al cabo de la humanidad entera, ni es una habilidad especial, mezcla de fortuna e ingenio, para mantenerse en el poder sin ser asesinado, sino ese humilde esbozo de unas libertad pensada como la conjugación de dos rechazos gemelos, la tiranía y la servidumbre. Estas dos condiciones degradadas se comunican por la misma incapacidad de mandar sobre uno mismo, que en el pensamiento antiguo se opone a aquella otra forma de gobernar que no quita la dignidad al hombre, sino que se la otorga, y que se comprendía en la fórmula clásica de la ciudadanía: gobernar y ser gobernado [...] La libertad en Marco tiene, pues, de estos referentes imaginarios, dos figuras de contraste, esclavo y tirano, contempladas desde una perspectiva que las iguala y las neutraliza en la imagen de un poder sin autodominio, forjada en curiosa comunión por la poesía y la filosofía. De las dos, la tiranía es el paradigma, y la esclavitud, uno de sus rasgos distintivos y de sus apariencias más llamativas. El tirano no solo es esclavo de sí mismo, sino que fomenta su esclavitud en los demás" Campos (2010, p.48). 
básicamente el mismo principio. El individuo debe sufrir una emancipación, primero frente a sí mismo, en tanto no dejarse dominar por las pasiones, en mantener una conducta moderada, disciplinada frente a los propios deseos y en ese sentido, poder ser libre. La autonomía trata también de la separación del individuo de la voluntad del gobernante, quien puede desear tomar decisiones en el ámbito íntimo del hombre.

A diferencia de Hobbes hay autocontención y existe también la construcción de un criterio sobre el espacio íntimo del hombre, esto es, el entorno de sí mismo, en el que sus conductas, opiniones o tendencias no sean dañinas ni beneficiosas para nadie, sino que esto únicamente le pueda afectar a él. En consecuencia de este principio de autonomía, en Kant se puede comprender la capacidad del hombre para construir sus preferencias, para edificar sus fines, en términos del punto anterior, se diría que el individuo se encuentra en capacidad para llenar de contenido el concepto de felicidad, de ponderar su importancia y los pasos para llegar hasta esta. Únicamente él puede decidir sobre los fines que persigue, para esto no será presa de la dictadura de sus pasiones, ni tampoco del autoritarismo de quien tiene el gobierno de los hombres. Precisamente todo hombre, desde su autonomía, se tomará como un fin en sí mismo, como un individuo que se impone a sí mismo unas normas de conducta, como un auto legislador de sí. Veamos:

En efecto; el fundamento de toda legislación práctica hallase [sic] objetivamente en la regla y en la forma de universalidad, que la capacita para ser una ley (no simplemente una ley natural), según su primer principio, hallase, empero subjetivamente con el fin. Mas el sujeto de todos los fines es todo ser racional, como fin en sí mismo, según el segundo principio de donde sigue el tercer principio de la voluntad, como condición suprema de la concordancia con la misma razón práctica universal, la idea de la voluntad de todo ser racional como una voluntad legisladora. Según este principio, son rechazadas todas las máximas que no puedan compadecerse con la propia legislación universal de la voluntad. La voluntad, de esta suerte, no está sometida exclusivamente a la ley, sino que lo está de manera que puede ser considerada como legislándose a si propia, y por eso mismo, y solo por eso sometida a la ley (de la que ella misma puede considerarse autora) (Kant, 2005, p. 120).

Esto es lo que podría denominarse un principio racional del Derecho Natural. La ley para el filósofo de Königsberg no es un problema que depende de la capacidad coactiva del príncipe para ser impuesta, sino que tiene que ver con el ámbito íntimo del hombre, esto es, con su disposición a aceptarla como válida y a integrarla en su arbitrio interno como guía de su conducta. La ley lleva en este punto atravesado el concepto de deber, es decir, la ley se cumple, desde el ámbito Kantiano, más por un sentido del deber que por temor o por el sentido de la obligación. No obstante, para que esto sea así, la norma, cualquiera que esta sea, debe pasar el filtro de aplicación universal a todos los hombres por igual, quienes hacen de su aplicación particular, 
un modo de comportamiento general a gran escala para todos los individuos. Esta es la gran diferencia entre una legislación como efecto del gobierno de un tirano, que el de un gobierno que es expresión de la elaboración moral, no de la cultura, pero sí de la razón.

La autocontención del hombre y sus mandatos, tendrán mucho que ver con el modo como se construyen los mandatos de modo externo al hombre, pues deben ser la manifestación de su moderación y buen juicio. Se unen aquí entonces la noción de la objetividad de la ley externa al hombre, con la subjetividad que orienta sus acciones. Como consecuencia, así como debe contenerse el individuo en su conducta, en la misma medida, las normas que le gobiernen deben ser moderadas y universales, al menos si se aspira a que estas encuentren refugio en su noción de deber. Lo que separa a los hombres de la tiranía será aquí, la universalidad de las normas y la coherencia entre ellas, dada precisamente por los modos racionales que hasta aquí se han construido.

\subsection{La fórmula del Reino de los Fines}

Cada hombre, bajo la mirada kantiana es un fin en sí mismo, y más que eso, es un productor de fines, su existencia como ser racional está dedicada a la consecución de esos fines, -El axioma fundamental de la Acción Humana en Ludwig von Mises como mejoramiento continuo-. Siendo así, el problema cardinal que tiene toda la metafísica de las costumbres, es volcarse sobre el tema de la diversidad de fines y su posibilidad de coexistencia. Precisamente, toda la estructura racional que se ha expuesto aquí tiene que ver con el modo de construcción a priori de una plataforma bajo la cual pueda existir una convivencia de estos fines, aun cuando los intereses de los hombres puedan aparecer como contrapuestos. Justamente el mecanismo de leyes de construcción universal, con la coherencia como principio fundamental y el deber como soporte, apuntan a la generación de un espacio en el que puedan ser compatibles lo que antes se entendía como contrapuesto. De allí la importancia que hasta ahora se le ha dado a la autocontención de las pasiones y la moderación de la conducta.

Por reino entiendo el enlace sistemático de distintos seres racionales por leyes comunes. Mas como las leyes determinan los fines, según su ley universal, resultará que, si prescindimos de las diferencias personales de los seres racionales y asimismo de todo contenido de sus fines privados, podrá pensarse un todo de todos los fines (tanto de los seres racionales como fines en sí, como también de los propios fines que cada cual puede proponer) en enlace sistemático; es decir, un reino de los fines, que es posible según los ya citados principios (Kant, 2005, p.123).

Para hacer posible ese reino, se necesitarán entonces un "enlace sistemático" en el que los hombres estén igualmente sostenidos a "leyes comunales". Aquí el filósofo toma en sus manos el problema que había sido propuesto por Adam Smith desde la 
economía: la convivencia de intereses contrapuestos. Más su intención no es describir el mecanismo por medio esto se hace posible en el mundo de la producción y el consumo, sino que la mirada de Kant apunta a establecer desde la filosofía una base cierta mediante la cual pueda ofrecerse un terreno institucional, que haga posible "la convivencia de fines", esto es en términos económicos, el proceso de producción material de la riqueza y su apropiación pacífica por medio del intercambio comercial a gran escala. Se asume aquí el problema de establecer un mandato legal y moral que pueda sostener esa infraestructura, y permita el avance tecnológico y el progreso material de las naciones y los hombres. La solución del problema del reino de los fines, se entenderá como la construcción de instituciones que propicien canales para la satisfacción pacífica y cohesionada de los fines. El Estado de derecho, la igualdad ante la ley y la coherencia como principio, serán la base institucional que soporte esta convivencia.

Si bien se ha establecido el principio de universalidad y coherencia como principios rectores de la construcción Kantiana, es necesario establecer que estos dos vendrán apoyados de un principio auxiliar que será la consecuencia inmediata de estos dos: el criterio de eficiencia dinámica. Tal como lo plantease Adam Smith bajo un escenario mercantil pacífico, es posible hacer compatibles los intereses de los individuos quienes muchas veces compiten por disfrutar de los mismos bienes, o quienes desean acaparar tanta riqueza para sí como sea posible. Y bajo este proceso y sin proponérselo como efecto de las consecuencias no intencionadas de la acción, terminan poniendo a disposición de sus semejantes lo mejor de sus propias capacidades, se pone a su servicio, no por caridad, sino precisamente por ese interés. Como efecto de esto, es que es posible señalar que un mundo de convivencia de los fines, tiene como adjunto un principio de eficiencia dinámica, en donde se maximiza la riqueza, no para un momento en particular, sino donde es posible establecer un proceso de creación y descubrimiento de nuevos modos de hacer y nuevas formas de producir, que serán puestas a disposición de los individuos, quienes verán elevarse cada vez más su nivel de riqueza y comodidad. Dicho en una palabra: el principio de coherencia en el derecho, posibilitará la convivencia pacífica entre los individuos, y allanará el camino para la convivencia de sus fines, esto es, para la compatibilidad de sus ambiciones y necesidades de enriquecimiento personal. El formalismo kantiano, tiene sentido dentro de un esquema de comercial. El formalismo jurídico de Kant es una pieza fundamental, no sólo de un mundo libre en términos políticos, sino de un mundo libre en términos económicos. La propuesta kantiana apunta en últimas al mercado.

Kant puede entenderse en últimas como un continuador de Adam Smith en el terreno de la simbiosis de la moral con la estructura orgánica de la sociedad. Ya anteriormente Adam Smith había propuesto un esquema de examen moral desde la razón, que tuviera como centro una valoración intersubjetiva en la que el hombre se valoraba a sí mismo, con la misma medida que valoraba a los demás, convirtiéndose esto en un radar de su conducta. El espectador imparcial, determinaba los límites de 
la moralidad pero establecidos racionalmente, y es la base sin la cual no es posible entender su propuesta de orden social liberal centrada en el mercado como mecanismo de integración social y política. Veamos la propuesta de Adam Smith (2004):

El principio según el cual aprobamos o desaprobamos nuestro propio comportamiento es exactamente el mismo por el que ejercitamos los juicios análogos con respecto a la conducta de otras personas. Aprobamos o rechazamos proceder de otro ser humano si sentimos que, al identificarnos con su situación, podemos o no podemos simpatizar totalmente con los sentimientos y motivaciones que lo dirigieron. Del mismo modo aprobamos o desaprobamos nuestra conducta, al ponernos en el lugar de otra persona y contemplarla, por así decirlo, con sus ojos, y desde su perspectiva, podemos o no asumir totalmente y simpatizar con los sentimientos y móviles que la influyeron.

El ser humano desea naturalmente no sólo ser amado, sino ser amable, es decir, ser lo que resulta un objeto natural y apropiado para el amor. Naturalmente teme no sólo ser odiado, sino ser odiable, es decir, ser lo que resulta ser un objeto natural y apropiado para el odio. No solo desea la alabanza, sino el ser loable, o ser un objeto natural y adecuado para el encomio, aunque en la práctica nadie lo alabe. No sólo le espanta el reproche sino el ser reprochable, o ser un objeto natural y adecuado para el reproche, aunque en la práctica nadie le reproche nada (pp. 221, 226).

Al igual que antes señalábamos que implícitamente Kant asumía la igualdad en los hombres, esta misma consideración puede asumirse en el filósofo escocés, más aún, la regla de juzgamiento de las acciones del hombre bajo el filtro de la moral obedecen igualmente a principios de universalidad y coherencia. Ya que el hombre es capaz de ejercer una especie de separación de sí y establecer una medida de sus acciones como si las estuviera viendo desde fuera, y con base en esa medida es que el hombre es capaz de contener su conducta, más en búsqueda del propio reconocimiento que en el aplauso que esté más allá de su propia conciencia. Ahora bien, si se mira con cuidado la fórmula kantiana de evaluación de una norma moral, bajo la cual esta es aceptable si se puede hacer de una conducta individual, una ley general, rápidamente se verá que no es más que una continuación del principio expuesto en las dos citas precedentes. Kant es un continuador de Smith en términos morales.

Immanuel Kant y Adam Smith desde su inspiración estoica atacan indirectamente la estructura del Estado Absoluto de Hobbes y su proyecto político de eliminación del individuo al hacer manifiesto un error de análisis en el que incurre Hobbes en su muy fino argumento. Si bien el Leviatán era el mecanismo de organización social por excelencia construido por el autoritarismo, este no podía funcionar de manera estable, bajo los condicionamientos antropológicos expuestos por el filósofo de Malmesbury. No es posible una organización social en la que los individuos atiendan a la ley simplemente por el temor a las represalias. Es necesario algún tipo 
de reconocimiento de la norma, algún modo de interiorización de moral y ley en el que se asuma su cumplimiento desde el deber. Esto por una razón esencial: los gobernantes siempre serán de menor número que los gobernados y aunque frágiles por separado, su fuerza unida bien podría lanzar al príncipe de su trono y lanzar a la hoguera sus leyes y decretos. Debe existir algún tipo de identificación entre moral y ley para establecer un orden social estable, y más aún, para garantizar un mínimo de convivencia de los fines, que no devenga en una guerra civil. La obligación política como fuente del cumplimiento de la ley necesita de manera expedita, algún tipo de aceptación y apoyo en para su cumplimiento, de lo contrario no funcionaria.

Así sucede que el ser humano, que solo puede subsistir en sociedad, fue preparado por la naturaleza para el contexto al que estaba destinado. Todos los miembros de la sociedad humana necesitan de la asistencia de los demás y de igual forma se hallan expuestos a menoscabos recíprocos. Cuando la ayuda necesaria es mutuamente proporcionada por el amor, la gratitud, la amistad y la estima, la sociedad florece y es feliz. Todos sus integrantes están unidos por los gratos lazos del amor y el afecto, y son por así decirlo impulsados hacia un centro común de buenos oficios mutuos. Pero aunque la asistencia necesaria no sea prestada por esos motivos tan generosos y desinteresados, aunque tiene los distintos miembros de la sociedad no haya amor y afecto recíprocos, la sociedad, aunque menos feliz y grata, no necesariamente será disuelta. La sociedad de personas distintas puede subsistir, como la de comerciantes distintos, en razón de su utilidad, sin ningún amor o afecto mutuo; y aunque en ella ninguna persona debe favor alguno o está en deuda de gratitud con nadie, la sociedad podría sostenerse a través de un intercambio mercenario de buenos oficios de acuerdo con una evaluación consensuada. Pero la sociedad nunca puede subsistir entre quienes están constantemente prestos a herir y dañar a otros. Al punto en que empiece el menoscabo, el rencor y la animadversión recíprocos aparecerán, todos los lazos de unión saltaran en pedazos y los diferentes miembros de la sociedad serán por así decirlo disipados y esparcidos por la violencia y oposición de sus afectos discordantes. Si hay sociedades entre ladrones y asesinos, al menos deben abstenerse, como se dice comúnmente, de robarse y asesinarse entre ellos. La beneficencia, por tanto, es menos esencial para la existencia de la sociedad que la justicia. La sociedad puede mantenerse sin benevolencia, aunque no en la situación más confortable; pero si prevalece la injusticia, su destrucción será completa. (Smith, 2004, pp. 182-183).

Smith propuso igualmente desde su perspectiva el problema de la convivencia de fines, es más, el problema del alcance de la felicidad como expresión de esa multiplicidad de fines. Para que pueda darse esa convivencia es menester que exista una institucionalidad generalmente aceptada que pueda proveer justicia, para que los fines coincidentes o contradictorios puedan coexistir. Smith no logra desarrollar el formalismo Kantiano de una metafísica de las costumbres a modo a priori, pero sí 
deja el problema suficientemente expuesto, y brinda una solución desde el punto de vista moral - el espectador imparcial- y su correspondencia desde el mercado - la mano invisible-, más se ve imposibilitado en formar un criterio objetivo en el que se pueda establecer una asociación cierta entre moral y ley, y donde el cumplimiento de la ley integre a la cuestión moral como una parte sustantiva de esta. No obstante, el mensaje que queda en Kant y Smith es que se requiere un Estado de Derecho que contenga la acción humana si esta corrompe los límites de la moral, afectando la paz y bienes de sus congéneres. Esto será típico de las naciones comerciales, según nos lo deja entrever Adam Ferguson (2008), contemporáneo y compañero de Smith en la Ilustración Escosesa:

De las naciones que habitan en esas partes de la tierra, o en algunas otras regiones menos cultivadas, algunas deben su subsistencia esencialmente a la caza, a la pesca o a los productos naturales del suelo. Dan poca importancia a la propiedad y apenas encontramos en ellas algunos principios de subordinación o de gobierno. Lo pueblos que poseen rebaños y dependen del pastoreo para su subsistencia saben lo que es ser pobre y rico. Conocen también las relaciones de patrón y cliente, de amo y sirviente y son clasificados con base en su fortuna. Esta distinción crea una diferencia esencial de carácter y ofrece la posibilidad de conocer dos condiciones a partir de las cuales poder considerar la historia de la humanidad en los tiempos rudos: el estado salvaje, que desconoce la idea de la propiedad; y el estado de barbarie, donde la propiedad, sin estar protegida por las leyes es el principal objeto de cuidado y deseo. Es evidente que la propiedad es una consecuencia del progreso. Además de unas particularidades que son resultado del tiempo, se requiere de algún método que defina la posesión. Todo deseo de propiedad procede de la experiencia, y la destreza que permite adquirirla o aumentarla requiere un determinado hábito de actuación que, poniendo la vista en metas lejanas, supera la disposición natural hacia la pereza o el placer. Este hábito que se adquiere lentamente es, en realidad, lo que distingue a las naciones que alcanzaron el dominio de las artes mecánicas y del comercio (Ferguson, 2008, p.129).

Tal como lo propone Hirshman (1978) en su obra Las pasiones y los Intereses, el mundo moderno asistió a la transformación del concepto económico, de una mirada peyorativa al enriquecimiento hacia una que lo reivindicaba y hasta lo enaltecía. Europa al abandonar la edad media, se introduce en una profunda revaloración de sí, en lo que Hazard (1988) llama una "Crisis de la Conciencia Europea". La cual inicia prácticamente el espíritu moderno al proponer continuamente un volver en sí para revalorar lo que se daba como cierto, y tratar de establecer desde la desazón, la ignorancia y la duda, unos fundamentos más firmes que brindaran solides a la ciencia, la política, la moral, la religión. Europa lanzó abajo buena parte de sus cimientos, y buena parte del esfuerzo de Kant puede comprenderse como la lucha por establecer una base sólida de aquello que había caído por su propio peso hacía 
mucho tiempo (Hazard, 1988, p. 376). Curiosamente su propuesta, tal como la de muchos del renacimiento, era tomar los conceptos latinos, en este caso el estado de derecho y el concepto de persona como la igualdad ante la ley. Recuérdese que el propio Kant habla tanto de la importancia de la división del trabajo, como del espectador imparcial en su obra, aunque no profundice en ello, pero es innegable que el filósofo escocés dejó una huella profunda en la estructura conceptual de su colega Prusiano. Por esto no debe sorprender que el criterio de universalidad y coherencia esbozado en Smith y desarrollado en Kant tenga como consecuencia última el reino de los fines y haga posible la maximización de la riqueza en términos dinámicos. En este reinado de los fines será posible que los hombres puedan combinar sus esfuerzos de un modo pacífico.

\subsection{El Problema de los fines y su convergencia: información y coordinación}

"Dimidiumfacti, quicoepit, habet; sapereaude"

Horacio

Si bien los tratadistas del derecho, la ética y la economía bajo la tradición occidental habían considerados a estos campos de estudio como sistemas de comprensión altamente vinculados, implicados desde su misma naturalezas, inseparables entre sí. La modernidad logró una separación efectiva entre estas disciplinas, ciencias o campos de estudio. El pensamiento occidental muestra esta unidad de tratamiento interdisciplinar como un hecho recurrente al menos desde Aristóteles hacia adelante. La lista es muy larga y podría ocupar varias páginas sólo con los nombres de sus protagonistas, pero para referencia del lector, puede tenderse una línea continua de este espíritu "holístico" a la tradición medieval de Santo Tomás de Aquino, San Agustín de Hipona - reconocido jurista-, pasando por los escolásticos españoles Domingo de Soto Francisco de Vitoria, Tomás de Mercado y Juan de Marian, hasta llegar a Francis Hutchinson, David Hume (2011), Adam Ferguson (2008) y el muy reconocido Adam Smith quien más que economista de oficio, era estudioso de los campos del Derecho y Filosofía moral, y que sólo como extensión de estos asimila el problema económico. Bajo esta sucesión de autores, suscrita en el marco del derecho natural se hace posible dar contenido sustantivo a la limitación de la acción humana en la búsqueda de sus imperativos hipotéticos y categóricos.

El derecho según la línea de tradición Escolástica-Escocesa-Austriaca-Liberalse propone como una institución bajo la cual el hombre pueda usar su propio conocimiento para alcanzar los fines que él libremente determine. Del mismo modo en que los precios toman forma a lo largo de intensos procesos de "procreación" renovadora de esquemas de producción, distribución y consumo - los cuales a su vez pueden ser divididos en partes infinitesimales, sujetas de innovación y mejora constante por parte de la mente que se relaciona con ella por medio del trabajo, el diseño, u ejecución en la línea productiva-. Del mismo modo, el derecho y su expresión 
particular, la ley, deben servir para que se pueda acumular y hacer uso de tanto conocimiento como sea posible. Esto posibilita una vida en la que el hombre pueda articular sus instintos particulares, esto es, sus deseos -pasiones-, con la estructura orgánica de la gran sociedad. En lo que Hayek llamaun “orden espontáneo como articulación descentralizada de decisiones individuales", una sistematización a gran escala de lo que Smith llama "mano invisible". Tal como lo expresara el economista austriaco:

En todo grupo mínimamente numeroso la colaboración se basará siempre tanto en el orden espontáneo como en una organización deliberada. No hay duda de que para muchas tareas limitadas, la organización es el método más indicado para una coordinación eficaz, pues permite adaptar fácilmente el orden resultante a nuestros deseos, mientras que cuando, debido a la complejidad de las circunstancias que hay que tener en cuenta, debemos contar con las fuerzas generadoras de un orden espontáneo, nuestro poder sobre los contenidos particulares de ese orden se limitan necesariamente. Sin embargo, el que estas dos clases de orden coexistan regularmente en toda sociedad de cierto grado de complejidad no significa que podamos combinarlos a discreción. Lo que efectivamente encontramos en todas las sociedades libres es que, si bien los grupos de hombres se unen en organizaciones para alcanzar determinados fines particulares, la coordinaciones de las actividades de todas estas distintas organizaciones, así como de los individuos es obra de las fuerzas que conducen a la formación de un orden espontáneo (Hayek, 2006, p. 69).

La ley como contención y no como dirección, puede ser el axioma fundamental sobre el que se apoye la mirada de la ley desde una perspectiva liberal austriaca que contemple la noción de orden social espontáneo como principio rector de la organización social.De acuerdo con Hayek (2006, p. 72):

Las reglas generales del derecho en que se basa un orden espontáneo tienden a un orden abstracto cuyo contenido particular o concreto no es conocido o previsto por nadie, mientras que tanto los mandatos como las reglas que gobiernan una organización ofrecen resultados particulares a los que aspiran quienes gobiernan la organización.

La ley no puede ni debe estar en cabeza de un sabio legislador, ni ser la expresión de su ingenio, tiene que ser capaz de ser sujeto de innovaciones sucesivas derivadas de la aproximación del conocimiento limitado y disperso que se encuentra esparcido a lo largo de toda la organización social acerca de los conceptos de lo permitido y lo censurable, ya no como limitación endógena del libre arbitrio interno del hombre, sino como la limitación a la que debe atender el hombre cuando este actúa en sociedad y su acción puede potencialmente ser dañina para sus semejantes. No se trata de un "precio" impuesto por un planificador centralizado, se trata en definitiva de una señal construida intersubjetivamente, que sirve de orientación y guía para que 
la búsqueda de la propia comodidad pueda redundar también en la comodidad de quienes le rodean, aun cuando no les conozca. Bajo la forma de los antiguos romanos, puede acudirse a la fórmula de Marco Aurelio (2010), según la cual, se busca evitar y reprimir por igual la tiranía y la servidumbre. Se trata por el contrario de propiciar un proceso de descubrimiento continuo en el que cada hombre pueda disponer como puede con su esfuerzo servir a los demás, y que sus semejantes a su vez le puedan proveer comodidad y reconocimiento.

No obstante, este axioma elaborado a la manera austriaca no tiene que ver en estricto con una postura filosófica que no tenga ulterior explicación, esto es, no se trata de un axioma que se quiera presentar como autoevidente o no sujeto de demostración- como modo de inmunización a la crítica, a la manera de los modelos de la economía neoclásica de chicago que como hija de la tradición cartesiana y su autismo acrítico, establece modelos basados en la irrealidad de escenarios idealessino que por el contrario, se trata de un principio elaborado a la luz de la propuesta antropológica y la teoría social sobre el surgimiento de las instituciones que provee la escuela austriaca. Se trata en definitiva, de una propuesta basada en la naturaleza íntima de lo que es el hombre, de sus modos de apropiación del conocimiento y de sus modos de organización e interrelación.

Desde Adam Ferguson, Adam Smith y Hayek ha quedado claro que la posibilidad de avance de la organización societaria, la Gran Sociedad se basa en el uso del conocimiento a gran escala; esto partiendo del entendimiento de las limitaciones de la mente humana que se encuentra determinada entre unas posibilidades de acumulación de información sumamente limitadas, pero en las que la especie como un todo se convierte en la suma de una memoria colectiva de procesos de adaptación continua a micro-experimentos que mediante el ejercicio continuo del ensayo y error van estableciendo conexiones eficientes entre los deseos del hombre y los medios que posee, refinando los mecanismos de acción y llevando al hombre cada vez más cerca de sus aspiraciones materiales, aun cuando estas puedan ampliarse tan prontamente como se alcanza un nivel más avanzado de productividad y desarrollo económico. El neurólogo español Santiago Ramón y Cajal logó establecer que el ordenamiento mental del hombre, lo que llamamos orden sensorial corresponde a interrelaciones entre secciones del cerebro que se estructuran como auténticas autopistas de información que van refinando los modos de comprensión y entendimiento a medida que se va recibiendo nueva información, y esta información se va solapando sobre la anterior modificando los modos de comprensión. En este sentido, se entiende como un proceso paralelo de clasificación, acumulación y reclasificación de información. Basándose en él Hayek (2004) propondrá:

El sistema de conexiones mediante el que los impulsos pueden trasmitirse de neurona a neurona, que, por tanto, es la posición del impulso individual o grupo de impulsos en el conjunto del sistema de dichas conexiones lo que le da su cualidad distintiva; que este sistema de conexiones se adquiere en el curso del desarrollo de las especies y del individuo mediante algún tipo de experiencia o aprendizaje; y que, por tanto, en cada estadio de su 
desarrollo, reproduce ciertas relaciones existentes en el entorno físico entre los estímulos evocados por los impulsos (p.118).

La capacidad de entendimiento humana esa demás por relación de conceptos que por la simple acumulación de información. Estos descubrimientos fisiológicos del neurólogo español, logró poner en términos biológicos lo que David Hume (2011) había propuesto desde la intuición y la filosofía en su modo más abstracto, pero más social a saber, que la naturaleza humana y su entendimiento depende de los códigos de interpretación que sean puestos en la mente por la estructura cultural de la educación y la costumbre de los padres, familiares y el entorno más inmediato. Sin embargo, las conceptualizaciones heredadas constituyen un fundamento pero no una estructura monolítica. La comprensión humana, según la entendía el escoses, corresponderá a un proceso interactivo en la que el hombre va transformando las conceptualizaciones que le son entregadas previamente, en la medida en que estas puedan servir de manera efectiva como orientación en el universo social en el que el individuo se encuentra inmerso, pero del que es partícipe, transformador y arquitecto.

Nuestras ideas no producen en su primera aparición impresiones que le correspondan, ni percibimos color alguno o sentimos una sensación simplemente por pensar en ello. Encontramos por otra parte, que toda impresión -sea de la mente o del cuerpo- es seguida constantemente por una idea que semeja esa impresión, y que difiere de ella tan solo por sus grados de fuerza y vivacidad. La conjunción constante de nuestras percepciones semejantes es una prueba convincente de que las unas son causas de las otras; y que nuestras y esta prioridad de las impresiones constituye una prueba igualmente convincente de que nuestras impresiones son causas de nuestras ideas, y no nuestras ideas de nuestras impresiones (Hume, 2011, p.45).

Para Rodolfo Llinás (1994), Médico y Neurólogo Colombiano:

El contenido sensitivo no es más que una serie de simplificaciones del contenido del mundo externo determinadas por las propiedades físicas de nuestros órganos sensoriales [...] De manera similar, la representación interna que se deriva de tal especificación sensorial está profundamente restringida por las capacidades "computacionales" del cerebro" [...] Este punto de vista implica que el modelo del mundo que surge en nuestra mente durante el desarrollo de niños a adultos está regido por las interacciones entre las predisposiciones innatas del cerebro y las adquiridas por la experiencia sensorio motora (pp. 4,13, 5).

Basado en esto, Hayek se atreve a decir que razón y civilización han avanzado juntas. La razón no se trata en de un objeto perfectamente desarrollado, establecido y definido, se trata más bien de una potencia, de una posibilidad por desarrollar, de un sentido por mejorar desde la experiencia y el libre albedrio. La razón así entendida recuerda el concepto de alma que tanto pregonaba Sócrates como un algo abstracto que se encontraba dentro del hombre, pero que no era innato en él, sino al que se llegaba por medio del estudio y el desarrollo de la sabiduría. La 
capacidad de entendimiento así entendida, lo que hoy denominamos como razón, era entendida desde la Sócrates el cultivo del espíritu y su ejercicio permanente. La civilización será entonces el producto inevitable del desarrollo de la razón, de una ampliación a gran escala de la capacidad de entendimiento de los individuos y de su organización a gran escala como un gran organismo con múltiples posibilidades de interrelación y desarrollo. La capacidad tecnológica de cualquier organización social u agrupamiento de hombres, entendiéndola como país, región o comunidad es la expresión del desarrollo de ese entendimiento y de su aplicación sobre problemas prácticos. Es esta y no otra la raíz del desarrollo tecnológico, el avance de la ciencia y de la Riqueza de las Naciones, tal como nos lo reiterará el profesor de filosofía moral de la Universidad Glasgow, Adam Smith. Libertad individual y crecimiento económico se articulan desde la noción del libre albedrio, como axioma fundamental y límite del ejercicio del Estado y la producción de la ley. Esta conexión entre libre albedrío, desarrollo tecnológico y crecimiento económico, nos la brinda Ludwig von Mises (2003) en los siguientes términos:

Libre albedrio significa que el hombre puede perseguir fines específicos porque conoce algunas de las leyes que determinan el fluir de los acontecimientos del mundo. Hay una esfera dentro de la cual el hombre puede elegir entre diferentes alternativas. No está como otros animales, inevitable e irremediablemente sujeto a la opción de un destino ciego. Puede, dentro de específicos y estrechos límites, desviar los acontecimientos del curso que tomarían si se les dejara solos. Es un ser que actúa. En esto consiste su superioridad sobre los ratones y los microbios, las plantas y las piedras (p.206).

Jesús Huerta de Soto (1992) deja esto muy en claro cuando establece que el hombre como individuo, se comprende entonces como una fuente de habilidades intransferibles, de talentos inalienables de los que sus congéneres solamente pueden servirse, sin aspirar nunca a que se les transfiera por completo mediante el uso de manuales o instrucciones precisas el secreto de su habilidad, el aprendizaje de las labores de una generación a otra no se da entonces por la aplicación incontrovertible de una manual de funciones, sino por los desarrollos que los individuos lograrán establecer a partir de los conocimientos entregados por sus antecesores. La humanidad se encuentra inexorablemente "destinada" a la búsqueda del mejoramiento continuo, es su naturaleza. Tal como lo propone el economista austriaco Ludwig von Mises (2006) "la acción humana es el paso de un estado menos satisfactorio a otro más satisfactorio" Si bien los resultados no siempre dan lugar a una mejora constante en el contexto social y productivo - económico- la búsqueda de mejoramiento es la esencia misma del ser humano, en razón de esto, se ve siempre enfrentado en la búsqueda de mejores medios para sus fines, del desarrollo de herramientas tecnológicas y organizativas en procura de una vida más cómoda. El avance de las organizaciones humanas, su mejora material más que basarse en una amplia división del trabajo y una constante mejora tecnológica, se basa en la división y expansión del conocimiento de orden práctico que habita en cada uno de los seres humanos, su expresión son los 
bienes finales destinados al consumo, y los bienes de capital, destinados al proceso productivo, la expansión de la información es tan amplia como individuos pueda haber en el mundo, en tanto cada uno de estos se constituye como un depósito de información y una potencia creadora de la misma.

Justamente por la dispersión de la información y su carácter factico no transferible es por lo que se erige desde la escuela austriaca el llamado teorema de la imposibilidad del socialismo (Mises, 2007), según el cual el planificador central no podrá establecer el cálculo económico necesario para coordinar a los agentes económicos en sus decisiones de producción y consumo. Igualmente, el planificador no podrá acceder a la información en tanto esta no ha sido creada, toda vez que esta depende del proceso continuo de creación que se encuentra en cabeza de los millones de individuos. Así entendido, la idea de la planificación centralizada de la economía y su consecuencia inmediata: la fijación de precios contienen la misma fórmula del fracaso que contiene el ánimo de establecer las leyes en cabeza de un sabio legislador que busca establecer las mejores normas para "maximizar la riqueza". En ambos casos, la planificación dependerá de la limitada información que tiene quienes hacen la ley y quienes imponen el precio, sin embargo, esto se hará a espaldas de la producción de información esparcida por todo el organismo social, dando al traste con el objetivo en clave utilitarista de proveer felicidad al mayor número o su correspondiente en términos de economía neoclásica de maximización de ganancias.

Por la estructura misma de la naturaleza humana, el derecho basado en el criterio de la eficiencia se encuentra condenado al fracaso y a condenar al hombre a lo que Thomas Hobbes (2006) llamaría una vida pobre, brutal y corta; aunque en esta oportunidad no por la ausencia del Leviatán, sino por la acción misma de éste, como la metáfora de un artilugio que se vuelve contra su creador. Si bien el espíritu del derecho positivo en términos modernos se encuentra concebido de manera muy cercana a la noción cartesiana en la que la legislación es mejor en tanto es concebida por la mente de un gran sabio, y no como el resultado de la intervención de millones de individuos, su espíritu de cientificidad moderna ha lanzado por tierra la coherencia entre las normas que promueve el legislador, en tanto estas obedecen más al capricho de quien hace la ley, de quien la promueve o de quien induce su redacción. Se trastoca así el principio de la eficiencia, en la misma medida que el principio de la coherencia.

\section{DE LA LEY COMO LÍMITE. EL PROBLEMA DE LA INFORMACIÓN Y EL CONOCIMIENTO EN LA LEY COMO PRECIO}

"Non ex regula iussumatur sed ex iure quodest regula fiat" Juluis Paulus

En virtud de carecer una regla cierta que indique con precisión qué es lo que debe hacer el hombre para actuar, puesto que la libertad es la raíz misma de su capacidad creativa y de su capacidad cognitiva. No corresponde a la legislación 
establecer modos de hacer sobre los hombres o imponerle conductas por medios exógenos a su propio ser. En clave de la escuela neoclásica y del ADE de chicago, no debe existir una imposición de la ley como precio. Pues no se puede entender al ser humano como artificio mecánico que actúa "A entonces B” para todo momento y lugar; sino que debe entendérselo como un continuo buscador de medios. La ley, desde la perspectiva liberal austriaca, no es una imposición del legislador que indica claramente la conexión entre medio y fines, lejos de esto, lo que hace es tender un puente entre lo moralmente aceptable, lo socialmente admirable y lo legalmente admisible, en la misma medida, se entiende la ley como contención, como límite, en donde se establecerá también un puente entre lo moralmente no aceptable, lo socialmente censurable y lo legalmente inadmisible.

La ley no habita ni limita en el arbitrio interno de los hombres, pero sí es la expresión de este, no aspira a introducirse en el ámbito privado de la conciencia y las acciones íntimas del individuo, pero sí establece una frontera de lo permisible -coactivamente exigible- en la interacción del hombre con sus congéneres en el espacio público en donde ya el hombre no se entiende únicamente con su conciencia o su auto criterio, sino donde sus acciones pueden llegar a ser potencialmente dañosas para su medio mediato e inmediato, pues, al hombre formar parte del organismo, sus acciones pueden constituirse en la semilla del entendimiento o en el motivo de la discordia y el enfrentamiento cuando los intereses entre los hombres puedan encontrarse.

La ley que niegue la libertad del hombre, es decir, de su capacidad de búsqueda y práctica de medios para satisfacer sus necesidades más sentidas, no sólo va en contra de la razón como propondría Kant en su Crítica de la Razón Pura, sino que va en contra del mismo hombre, de su aspecto más sustantivo y definitorio, esto es su libertad y su necesidad innata de procurarse cada vez una mejor situación mediante los medios que considere necesarios - estando estos en conjunción con el programa de mejoramiento de sus congéneres-.

El estado en que un hombre no se halla sujeto a coacción derivada de la voluntad arbitraria de otro o de otros se distingue a menudo como libertar "individual" o "personal" de otro o de "otros"

La libertad así entendida -Hayek y su visión de libertad negativa-, no se constituye como un elemento de orden exclusivamente filosófico con alcances sobre el mundo de lo político, sus alcances son también y de modo idéntico, profundamente económicos, negar la libertad, imponer los medios y cercenar la creatividad humana, reduce al hombre no sólo a la servidumbre política, sino a la miseria económica, reduce al hombre no sólo a la minoría de edad y resta su capacidad de autodeterminación, sino que lanza al hombre sobre la rudeza de la escasez y la precariedad de medios para satisfacer sus necesidades más inmediatas.

En clave de la ilustración escocesa, podríamos decir, que la riqueza de las naciones, así como la de los individuos, depende directamente de su capacidad para descubrir mejores formas de hacer las tareas a las que se enfrenta de manera 
cotidiana, y estas nuevas formas de hacer dependen de un largo - y en buena parte ininteligible- proceso de ensayo y error en el cual el libre albedrio del hombre se traduce directamente en mejoras tecnológicas, en invención de instrumentos, aparatos y máquinas, así también en invención de modos de organización en pequeña escala, en cómo disponer el tiempo y los recursos para producir más y mejor, en programar las actividades para que la tarea diaria se imponga cada vez con menos rigor sobre quién la lleva sobre sus hombros, en una palabra, en que cada día el hombre pueda enfrentar sus tareas con una mayor comodidad y pueda proveerse una vida más satisfactoria. En términos económicos esto puede resumirse en que el crecimiento económico requiere del ejercicio amplio de la creatividad humana y esta última haya su raíz e insumo principal en la libertad del hombre y en la no limitación de esta por un sabio legislador que le imponga unos medios específicos y unas metas definidas.

La utopía platónica basada en el sabio legislador se desvanece por la misma razón que la planificación centralizada del socialismo - aún bien intencionado-. La razón esencial se haya como lo indicábamos antes, en que el axioma de información completa del cual parten es ontológicamente imposible, es lo que llamamos un absurdo, pues la definición sustantiva va en contra de la cuestión adjetiva que pretende agregársele. Siendo la información siempre un objeto por descubrir, no existe algo como la información completa de la Escuela Neoclásica de Economía, o un conocimiento pleno de los fenómenos del mundo, pues la mente humana no se encuentra capacitada para contener todos los secretos del universo, ni tan siquiera los que tienen que ver con la naturaleza intima de su ser, como lo indicase Hume (2011), el hombre puede acercarse a la aproximación de la explicación de los fenómenos, mas nunca podrá tener entre sus manos la explicación de sus causas eficientes. El hombre no puede ni podrá acceder a todo el conocimiento sobre los fenómenos que gobiernan su naturaleza ni del entorno que le rodea. La información como modo de comprensión del mundo se halla en una mina inagotable en el entendimiento humano, aunque con la limitación fundamental de nunca poder acceder a los orígenes últimos de los acontecimientos. Tal como lo dijera Plutarco desde la Grecia de la antigüedad "La mente no es un vaso por llenar, sino una lámpara por encender". Así el hombre se encuentra inexorablemente condenado por una búsqueda sin fin de nueva luz sobre un mundo que no acaba de entender con claridad.

\section{DE LA LEY COMO LIBERTAD NEGATIVA. A MODO DE CONCLUSIÓN}

La forma que toma la ley en el contexto de la estructura Kantiana cuando ésta se llena del contenido austriaco, es la de la ley que más que hablar de un deber ser, propone aquello que no es admisible, es decir, lo que no debe ser. Así como la definición de libertad que se usa es de carácter negativa como ausencia de coacción, así también la ley como limitación y no como dirección, propone unas líneas rojas que no deben ser atravesadas so pena de castigo, más en ninguna parte establecerá 
una conducta exacta y establecida que una medios con fines. La ley no puede ni debe, bajo este contexto, establecer ningún tipo de conato coactivo sobre las preferencias de los hombres. No puede decirles, por ejemplo, a qué profesión se pueden dedicar, qué tipo de ropas usar, qué religión pueden profesar o el modo de educar a los hijos. Su labor será defender la integridad física, la vida, buen nombre y propiedades de los individuos. En razón de esto, siempre censurará determinado tipo de conductas del tipo: no robar, no agredir, no violentar las señales de tránsito, no dañar la propiedad ajena, entre otras. En definitiva, se trata de ofrecer un cauce de conducta mediante el cual el hombre establece un marco de conducta, en la que la procura de mejora de su propia situación no perjudica a quienes quieren con legítimo derecho mejorar la suya.

Ley y libertad no se presentan aquí como elementos de carácter contradictorio, sino que son dos componentes de igual naturaleza. La limitación de acciones potencialmente dañinas permite a todos los hombres la búsqueda constante de medios y la creación de información/conocimiento como fundamento de la acción humana y su búsqueda por la comodidad y la satisfacción. Es la limitación general y sin distinciones lo que permite a cada hombre sacar lo mejor de sí en el contexto social, permitir la división del trabajo, la especialización y la renovación tecnológica constante, con lo cual se da una convergencia entre la acción humana y el crecimiento económico sostenido. Con esto se da solución al problema de la información secuestrada a manos del legislador.

\section{REFERENCIAS}

Acton, J. E. D. (1999). Ensayos sobre la libertad y el Poder. Madrid: Unión Editorial. Campos, J. (2010). Estudio Preliminar. En Marco Aurelio. Pensamientos, Cartas, Testimonios (J. Campos Daroca, trad.). Madrid: Editorial Tecnos.

Ferguson, A. (2008). Ensayo sobre la historia de la sociedad civil (María Isabel Wences Simon, trad). Madrid: Editorial AKAl.

Garrido, M. (2005). Introducción, en Kant, Immanuel, Fundamentación para una metafísica de las costumbres. Madrid: Editorial Tecnos.

Hayek, F. A. (1997). Los fundamentos de la libertad. Barcelona: Folio.

Hayek, F.A. (2004). El Orden Sensorial. Los fundamentos de la psicología teórica. Madrid: Unión Editorial.

Hayek, F.A. (2006). Derecho, legislación y libertad. Madrid: Unión Editorial.

Hayek, F. A. (2007). Individualismo: El verdadero y El Falso. Madrid: Unión Editorial. Hayek, F. A. (2007). Nuevos estudios de filosofía, política, economía e historia de las ideas. Madrid: Unión editorial.

Hazard, P. (1988). La crisis de la conciencia europea. Barcelona: Alianza editorial.

Hirshman, A. (1978). Las pasiones y los intereses. México: Fondo de Cultura Económica. 
Hobbes, T. (1989). Leviatán (Carlos Mellizo, trad.). Madrid: Alianza Editorial Hobbes, T. (1997). Philosophical rudiments Concerning Goverment and Society. En: The English Works of Thomas Hobbes of Malmesbury. Abdindon: Routledge / Thoemes Press.

Hobbes, T. (2005). Elementos de Derecho Natural y Político. Negro, Dalmacio. Madrid: Alianza Editorial.

Hobbes, T. (2006). Leviatán (Carlos Mellizo, trad.). México: Fondo de Cultura Económica.

Huerta de Soto, J. (1992). Socialismo, cálculo económico y función empresarial. S.A. $2^{a}$. ed. Madrid: Unión editorial.

Hume, D. (2011). Tratado de la Naturaleza Humana. Madrid: Tecnos.

Kant, I. (2006). Fundamentación para una metafísica de las costumbres. Madrid: Alianza Editorial.

Llinás, R. (1994). La percepción como un estado pseudo-onírico modulado por los sentidos. Medicina, 36, 4-13.

Macpherson, C.B. (2005). La teoría del individualismo posesivo. De Hobbes a Locke. Madrid: Trotta.

Marco Aurelio. (2010). Pensamientos, Cartas, Testimonios (Javier Campos Daroca, trad.). Madrid: Editorial Tecnos.

Mises, L. (2007). La acción humana. Tratado de economía, $8^{\text {a }}$ ed. Madrid: Unión editorial.

Mises, L. (2003). Teoría e historia. Una interpretación de la evolución social y económica (Rigoberto Juárez-Paz, trad.) Madrid: Unión editorial.

Pérez y Soto, A. (2013). La información secuestrada: el modelo de servidumbre en Thomas Hobbes y su alternativa liberal austriaca en Friedrich August von Hayek. Tesis doctoral. Departamento de Economía Aplicada I, Facultad de Ciencias Jurídicas y Sociales. Madrid: Universidad Rey Juan Carlos.

Smith, A. (1979). Investigación sobre la naturaleza y causa de la riqueza de las naciones. México: Fondo de Cultura Económica, 1987.

Smith, A. (1759). Teoría de los sentimientos morales. México: Fondo de Cultura Económica.

Smith, A. (2004). La teoría de los sentimientos morales. Madrid: Alianza Editorial. 
